\title{
DE BLAUWE BOEKJES VAN MR. H.K. WESTENDORP
}

De kunstenares Betsy Westendorp-Osieck (1880-1968), vrouw van de eerste voorzitter van de Vereniging, Herman Karel Westendorp (1868-1941), hield een dagboek bij op de aankoopreis die het echtpaar in 1930 ondernam met Herman Visser (1890-1965), toen juist aangesteld als conservator van de Verenigingscollectie. Degenen onder $u$ die al langer lid van de Vereniging zijn, zullen zich wellicht het artikel van Maartje Draak uit 1985 herinneren, Het Rode Boekje van Mevrouw Westendorp. Ze schreef: 'Er zijn over deze reis optekeningen en brieven bewaard van Visser, en er moet een (min of meer officieel?) dagboek zijn geweest van Voorzitter Westendorp. (Is dat nog ergens?) In feite is het een onverhoopt buitenkansje dat de vrijmoedige opmerkingen van Betsie Osieck voor ons gespaard bleven in een onaanzienlijk rood aantekenboekje dat een veilige toevlucht heeft gevonden in de bibliotheek van het Rijksmuseum. De fortuin was ons niet volledig ter wille. Het bewaard gebeleven relaas begint plompverloren op 19 november 1930 te Kyoto, midden in een excursie naar Nara. Een voorafgaand - vergelijkbaar - boek of boekje is weg, en zoals altijd treurt de filoloog om het verlorene.'1

Nu hou ik mij al een tijd bezig met de verzamelingen van Westendorp en $u$ zult begrijpen dat ik stomverbaasd was toen de fortuin zich een paar jaar geleden alsnog deed gelden. Barones van Lynden vertelde me dat zij nog wat dingen uit de familie in haar bezit had en nodigde me uit voor een bezoek. ${ }^{2}$ $\mathrm{Na}$ een uitstekende lunch stond ik met open mond te kijken naar wat daar plotseling tevoorschijn kwam: een doosje met aantekenboekjes!! Maar liefst 39 deeltjes met aantekeningen die Westendorp tussen 1919 en 1939 maakte op zijn buitenlandse reizen (afb. 1). Vooral over Europese uitstapjes, maar ook waarachtig zes blauwe notitieboekjes over de reis naar Azië, met als slagroom op de taart het tot nog toe ontbrekende (zandkleurige) eerste deel van het Japanse reisverslag van mevrouw Westendorp (afb. 2). De treinreis terug ging snel voorbij onder het met rode oortjes bladeren in de verslagen ...

Nara. Zal ik er eindelijk toe komen een dagboek te beginnen zooals ik dat altijd deed op mijn reizen, en zooals ik totnogtoe verzuimde te doen? Het is wel jammer dat ik er niet toe kwam: nu blijft wel de indruk in groote lijnen, maar de kleine voorvallen, die, als men ze herleest, alles weer zoo duidelijk voor den geest brengen, zullen, vrees $i k$, spoedig vergeten zijn. Maar Bets heeft geregeld wat opgeschreven en ik heb mijn honderden foto'tjes. Napleiten helpt niet, laat ik dus probeeren tenminste iets van Japan vast te leggen.

Het is inderdaad jammer dit op de eerste bladzijde te lezen, want het was interessant geweest om Westendorps aandeel in de verwervingen in Indonesië

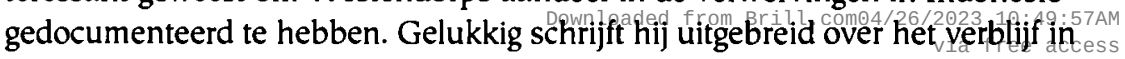



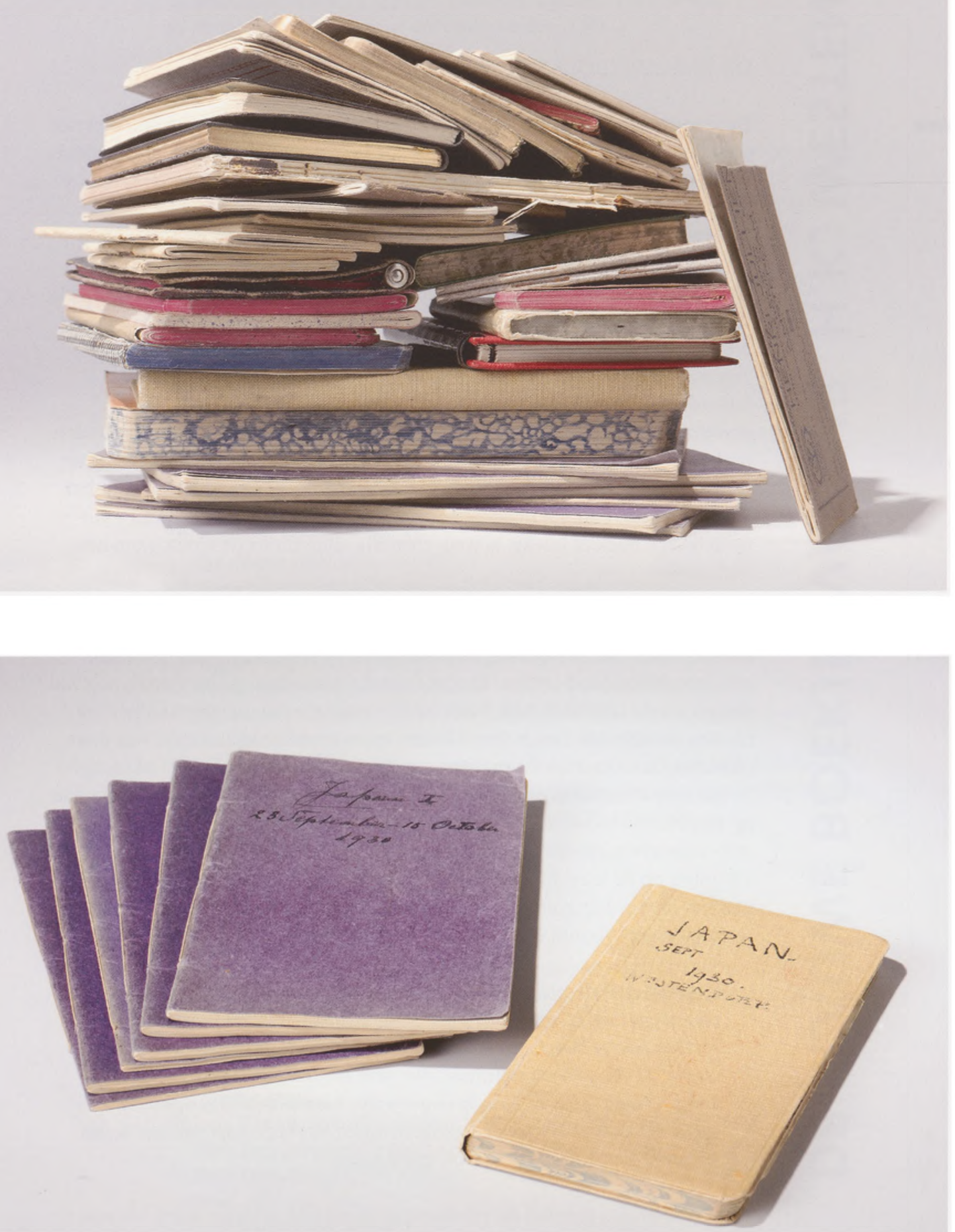

Downloaded from Brill.come4/26/2023 10:49:57AM via free access 


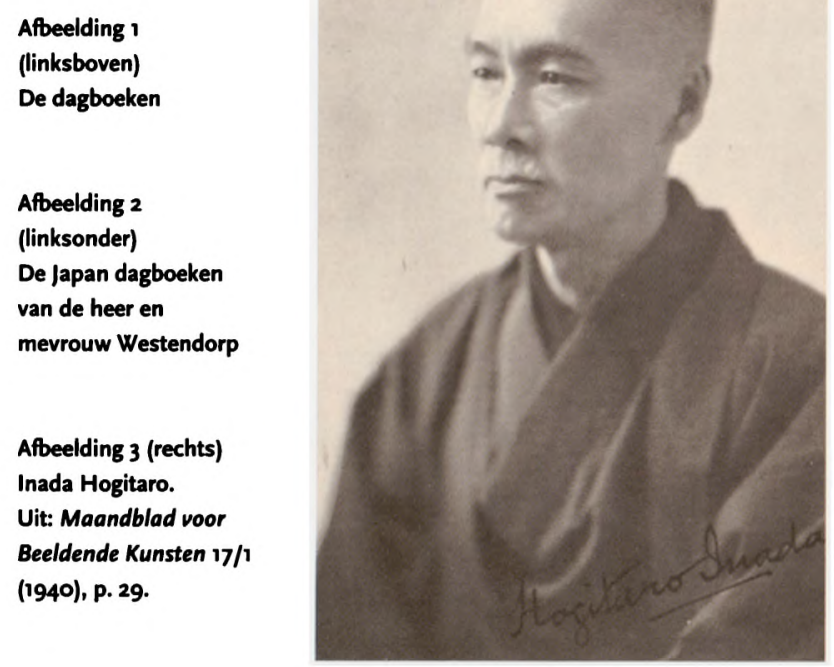

Japan. De negen weken van 23 september tot 1 december nemen deel I tot en met halverwege deel IV in beslag, oftewel 37 getranscribeerde pagina's A4. De overige twee delen zijn voor de rest van de reis - die uit ruimtegebrek voor een andere keer bewaard moeten blijven.

\section{De gids Inada Hogitaro}

De reis door Japan begint op 23 september in de aankomsthaven Kobe, waar Visser zich op de $27^{\mathrm{e}}$ bij het gezelschap voegt. Dat bestaat voor een groot deel van de reis uit de Westendorpen, Visser en de heer Inada (afb. 3). Inada Hogitaro (?-1940) is een kunstkenner uit Kyoto die eveneens in kunst handelt. Inada verkoopt bijvoorbeeld in 1914 schilderingen aan het British Museum, waar hij ook assisteert bij het catalogiseren van de collectie. ${ }^{3}$ Het kan goed zijn dat de Verenigingsleden hem al vanuit Europa kennen; in ieder geval is Visser al eerder met hem opgetrokken, op zijn eerste reis naar Japan in 1921. Westendorp kwalificeert Inada als 'gids', maar zijn rol is veel breder: mogelijke aankopen worden aan hem ter beoordeling getoond, Inada tolkt, regelt samen met Visser de afspraken om de collecties van musea, tempels en privé-verzamelaars te bezichtigen en verkoopt de Vereniging tijdens de reis een zevental voorwerpen. Daaronder zijn twee schilderingen, die hij in zijn huis laat zien.

Naar Inada, die ons opwacht in zijn kleine, maar gezellige huis. Er is een knap jong meisje ... dienstmeisje, dochter, nichtje?...

I. heeft vele schilderingen verzameld; de eerste (van hemzelf), Fugen op olifant, laat Fujiwara, bevalt mij al dadelijk zeer goed. Verder gaat het, maar we worden niet getroffen, tot we plotseling alle drie een „opdonder" krijgen van een kleine inktschildering, die (voor Y. 350) onmiddellijk voor het Museum wordt ingepikt. ${ }^{4}$

Het is wel zeker dat Inada van groot belang is geweest voor de contacten. Persoonlijke introductie is tenslotte van essentieel belang in Japan 0 m 10 : 49:57 AM 


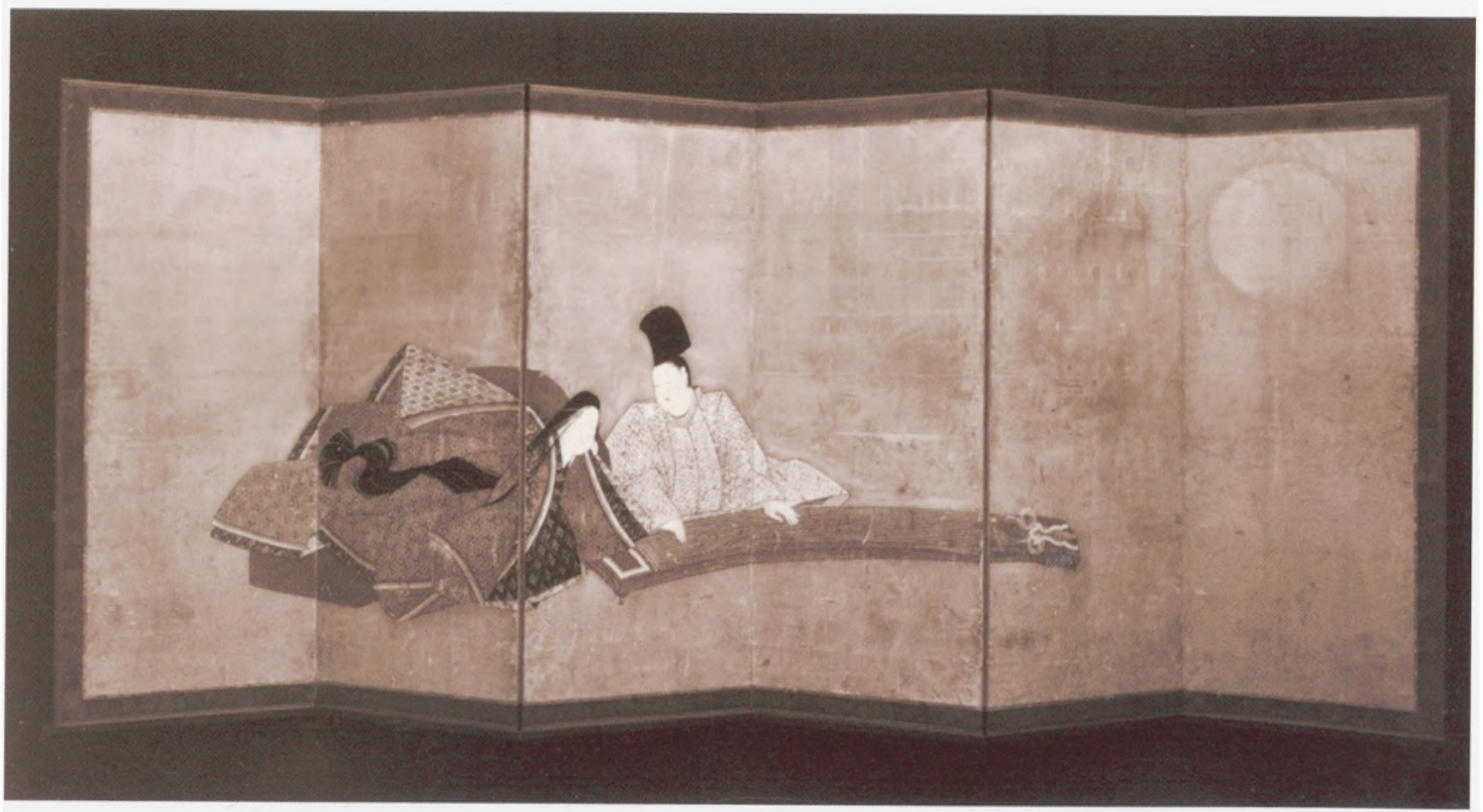

\section{Afbeelding 4}

Kamerscherm met kotospeler, inkt en kleur op papier, h. $144 \mathrm{~cm}$., br. $369 \mathrm{~cm}$. Japan, $18^{e}$ eeuw, Rijksmuseum Amsterdam, collectie WAK, AK-MAK-174 deuren te kunnen kijken die doorgaans gesloten blijven. Niet alleen bij tempels en musea, maar ook bij collega-handelaren, om voorwerpen van belang uit het magazijn of uit privébezit tevoorschijn te doen komen. Kortom, een sleutelrol voor Inada, die hij tot grote tevredenheid van de betrokkenen vervult. Visser schrijft in zijn Reisbrief uit Japan voor het Bulletin van de Vereniging:

Wij- onze Voorzitter en ondergeteekende, beiden voortreffelijk gesteund door den kunstenaars-kijk van Mevrouw Westendorp en door de kennis en relaties van den fijnzinnigen Kyôto'schen kunstkenner Inada (welbekend in Europeesche „japonisants"-kringen) -, hebben tot nu toe het volgende voor ons aanstaand Museum aangekocht: ${ }^{5}$

\section{Mevrouw Westendorp}

De steun van mevrouw Westendorp is inderdaad van belang geweest, vooral bij de het kiezen van schilderingen. Haar echtgenoot leunt op haar oordeel, zoals blijkt bij zijn aantekeningen over de verwerving van het enkele kamerscherm met een koto-spelende hofedele, vergezeld van een hofdame (afb. 4). Westendorp ziet het scherm op 2 november, samen met Visser bij de handelaar Shimizu in Tokyo.

Naar Shimidzu, waar V. gisteren is geweest. Het eenig werkelijk belangrijke is één scherm met 2 half-levensgrote figuren: man met muts achterop hoofd speelt de shamisen, ${ }^{6}$ terwijl een lady in courtdress naast hem zit. Wel bizonder interessant maar wat droog, en gezichten zijn dichtbij fijn, maar van de verte een witte plek. En dan de prijs, Y 3500!! Ben benieuwd hown Betsy het zal vinden. 
Naar Shimidzu om scherm nog eens te zien. Het is toch wel zeer belangrijk. Bets vindt het bizonder mooi. Ik ben echter vastbesloten niet meer dan Y 2500 te geven; wijs erop dat voor Japansche collectionneurs één scherm weinig waarde heeft, en dat het eene oog van de vrouwenfiguur niet intact is. Het slot is dat ik mijn zin krijg, en wij eigenaars worden van het scherm. ${ }^{8}$

Uit de dagboeken wordt duidelijk dat het proces van verwerving niet altijd zonder hobbels verloopt. Westendorp en Visser zijn het lang niet altijd eens en er vinden stevige discussies plaats, waarbij het voor Westendorp niet altijd duidelijk is waarom Visser nu enthousiast is over een bepaald voorwerp. Zoals bekend is Visser een gedreven mens, die buitengewoon energiek de zaken in handen neemt als hij van mening is dat iets moet worden verworven. Zonder zijn inspanningen zou menige aankoop niet tot stand zijn gekomen. Aan de andere kant is het wellicht goed dat Westendorp hem af en toe afremt, al is Visser daar niet gelukkig mee. Zo ook bij de handelaar Shimizu:

Na lunch man van hotel met een vriend bij Visser met een Fujiwara (?) Jizo, ongeveer $40 \mathrm{~cm}$. hoog, waarvan we gisteren foto zagen. Visser ineens weer vuur en vlam, wil dadelijk koopen, Y 1500. Ik aarzel, zal wel moeten geven, maar neem geen verantwoordelijkheid. Kan echter niet steeds veto-en. Kop bevalt mij niet, niet in overeenstemming met lichaam (te groot en hout suspect), en ook onderstuk beenen met voeten leelijk. We houden nog even aan. ${ }^{9}$

Op grond van advies, mogelijk van Inada, wordt het beeldje (afb. 5) toch verworven. ${ }^{10}$ Ook Westendorp realiseert zich dat Visser hier gelijk heeft:

Visser heeft oordeel gevraagd over de ons aangeboden sculptuur; het oordeel over den expert, die het "Gutachten" gegeven heeft, luidt algemeen gunstig, foto valt ook in den smaak, prijs schijnt zeer billijk. Dus verantwoord. ${ }^{11}$

\section{Westendorp en Visser}

De spanningen tussen Visser en Westendorp leiden er mede toe dat er langdurig gedelibereerd moet worden of er nu wel of niet verder naar Korea en China doorgereisd zal worden, zoals oorspronkelijk de bedoeling was. Westendorp schrijft hierover al op 9 oktober:

Aan déjeuner minder aangenaam onderhoud met Visser; het gaat niet goed tusschen ons. [...] 's avonds eenigszins stekelige discussie: naar Korea of niet? Het is wel een erg lange reis! ${ }^{12}$

Westendorp zoekt de oorzaak van de wrijving maar gedeeltelijk bij zichzelf.

Laat ik eerlijk zijn en toegeven dat ikzelf soms ook niet gemakkelijk ben geweest, zooals ik dat wél ben met menschen van mijn eigen ( $n u$ ja, het klinkt wat pedant maar er is geen ander woord) standing. ${ }^{13}$ 


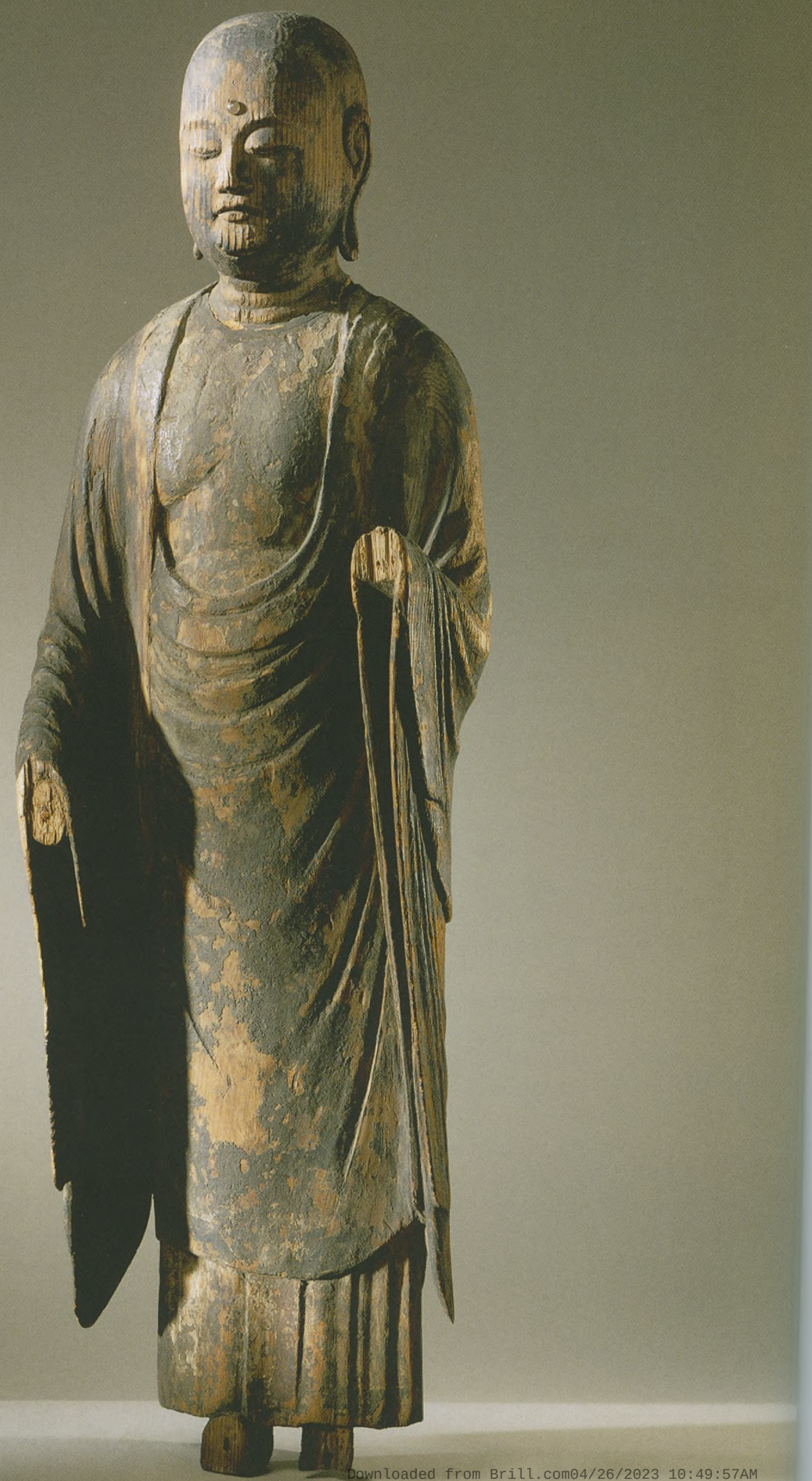


de andere ontgaan hem „Niemand is groot voor zijn kamerdienaar". Al past deze vergelijking zeker niet geheel, er zit toch wel iets in. ${ }^{14}$

\section{Afbeelding 5} Beeld van lizo, hout, h. $47 \mathrm{~cm}$., Japan, $13^{\mathrm{e}}$ eeuw, Rijksmuseum Amsterdam, collectie WAK, AK-MAK-116
Hoe het ook zij, het is maar de vraag of Westendorp erin slaagt bij Visser de juiste toon te raken als hij de problemen ter tafel brengt.

's Morgens in auto had ik gelegenheid Visser in allen kalmte te wijzen op zijn verkeerde houding; hopen wij dat het helpt! ${ }^{15}$

Uiteindelijk valt het besluit om het bij het Japan-bezoek te laten. Westendorp:

Ik moet nu beslissen wat verder te doen. Er is veel gepraat over Korea en Peking. De Hoeffelmans komen juist uit Peking, raden het aan, maar een beetje du bout des levres, want als $i k$ ze vraag of ze er nog eens heen willen, zeggen ze alle drie „neen”. Als men mij vraagt of ik nog eens naar Indië en Japan zou willen, zeg $i k$ volmondig "ja". Ze geven toe dat er veel aan vast zit, maar zijn blij ,het gezien te hebben". Ik heb een staartje van een typhoon en een aardbevinkje meegemaakt, en ben erg blij "het meegemaakt te hebben", maar daarom wensch ik toch niemand zoo iets toe. Het is er daarbij op het oogenblik al vinnig koud en we zijn op groote kou niet geëquipeerd. Ze hebben eenmaal 3 dagen achtereen het hotel niet kunnen verlaten, zoo boos weer was het. 't Spijt me van ganscher harte voor de lieve Bets, die haar zinnen erop had gezet, maar ... ik ben 62. Totnutoe gelukkig alles goed gegaan, maar dit zou, dat voel ik, mij te zwaar zijn. ${ }^{16}$

Mevrouw Westendorp, in een aantekening van de dag ervoor:

Heftig gesprek over eventueele reis naar Peking. Visser gaat niet omdat hij bronzen kocht voor Menten en roûte. Hij is bang voor infecties. Wij besluiten nu ook niet te gaan, temeer daar de Hoeffelmans niet opgetogen terug kwamen. ${ }^{17}$

Als we tussen de regels proberen te lezen, lijkt het erop dat Visser inziet dat gezien de verhoudingen voortzetting van de reis niet goed doenlijk zal zijn; Westendorp lijkt er niet heel erg op gebrand om in dat geval samen met zijn vrouw toch te gaan - zijn gezondheid zal later ook inderdaad niet goed blijken te zijn. Het echtpaar gaat op weg naar Angkor, maar na korte tussenstops in Shanghai, Hong Kong en Saigon besluiten ze vanwege hevige buikpijnen van Westendorp door te gaan naar Singapore, waar hij zonder resultaat in het ziekenhuis wordt onderzocht. Eenmaal aangesterkt besluiten ze toch naar Angkor te gaan, wat voor beiden 'een wens van jaren' is. Daarna keren ze via Saigon, Singapore en Sri Lanka weer naar huis. Visser blijft nog tot rond 18 december in Japan.

\section{Bezoeken aan collecties en kunsthandel}

De organisatie van de Japanreis ligt grotendeels bij Visser en Inada, die zo vriendelijk zijn om het op zich te nemen contact te leggen met museumdirecteuren, tempel-beambten en privéverzamelaars en daarmee afspraken te maken, zodat de heer en mevrouw Westendorp zich daar niet mee onledig hoeven te houden. Het echtpaar wil ook plaats in het schema inruimen voor 'sightseeing'; veel meer dan Visser, die steeds opnieuw de kunsthandel wil aflopen om te zien of er nog iets nieuws is binnengekomen. En dus maken de 
heer en mevrouw Westendorp een aantal uitstapjes met $z$ 'n tweëen; om het natuurschoon van de bossen in herfstkleur te bewonderen, de mausolea in Nikko te bezoeken, of de berg Fuji te zien liggen.

Ook ziet het gezelschap een groot aantal collecties. Zo bekijken ze de verzamelingen van de musea in Kyoto, Nara en Tokyo, zien ze in alle belangrijke tempels van Kyoto en Nara vooral veel sculptuur. Het is tekenend voor de goede contacten van Inada dat vrijwel overal voorwerpen uit de kast worden gehaald, zoals bij de uiterst belangrijke verzameling uit de $\mathbf{8}^{\mathbf{e}}$ eeuw van de tempel Shosoin. Bij grote verzamelaars gaan eveneens de deuren open: Nezu Kaichirô (1860-1940), later de oprichter van het Nezu Institute of Fine Arts in Tokyo; Markies Maeda (waarschijnlijk Maeda Toshinara (18851942), nakomeling uit een van de meest invloedrijke daimyô-geslachten, die Visser op de boot naar Japan had ontmoet); Baron Masuda Takashi (18481938), oprichter van het Mitsui concern en spin in het netwerk van verzamelaars van het gerei voor de Japanse theeceremonie; Baron Dan Takuma (1858-1932), bestuursvoorzitter van hetzelfde Mitsui-conglomeraat (op introductie van S.C. Bosch Reitz), en Markies Tokugawa Yoshichika (18861976), wiens familiecollectie nu het Tokugawa Art Museum in Nagoya vormt.

Het zien van de kunstcollecties geeft Visser en Westendorp perspectief bij de eigen zoektocht naar voorwerpen, die uiteindelijk resulteert in een 70-tal aanwinsten voor de Vereniging (Westendorp koopt natuurlijk ook het een en ander voor zijn eigen verzamelingen, voornamelijk theekeramiek en porselein), waaronder 27 schilderingen, 14 stukken lakwerk en 9 maskers. De totale kosten van de verwervingen bedragen een kleine 22.000 Yen, waarmee een hap van ongeveer 27.500 gulden wordt genomen uit de 150.000 van het in 1928 opgezette aankoopfonds. Daarvoor moet flink worden doorgewerkt. De dagen zijn gevuld met bezoeken aan de kunsthandel: Fukuda, Hayashi, Kita, Kitanaka, Tsuruki en Yamanaka in Kyoto; Shimada, Watanabe en Yokoyama in Tokyo; Kobayashi ${ }^{18}$ en Kurasawa ${ }^{19}$ in Kobe.

Het lieve leventje begint weer! Kunsthandel, und kein Ende! Eerst naar Fukuda (waar ik nog niet was, maar waar Visser portret van Kobo Daishi heeft gekocht, wat ik nog niet zag). Deze vertoont ons een wel importante Kamakura-schildering. Shaka met Boddhisatva's, in de bekende goudtechniek. Erg duur, Y 1000. Ook een haan en kip (Kakemono), pleasing. Zou zeer op zijn plaats zijn in groote schilderingen-collectie; eveneens Y 1000. Vele lakken, waaronder mij direct treft een suzuribaku met waaierdecor, prae-Tokugawa, die ik zeer graag zou aankoopen; de exhorbitante prijs, Y. 3500, is echter een onoverkomelijk bezwaar. Wat zijn er weinig goede lakken, en wat zijn de weinige goede reusachtig duur! Daarna naar Inada, die echter niets heeft wat ons aantrekt, alleen misschien een stuk van een muur, lak, met vogel, maar toch niet goed genoeg. Heeft voor mij 3 Oribe chaire verzameld, waarvan ik echter maar niet eens naar de prijs vraag. Daarna nog naar Hayashi, voor een Koyetsu doos (?), een in onze oogen leelijk zwart geval.

\section{Foto's}

Het beeld van de aankoopreis is nu behoorlijk compleet geworden, vooral in het totstandkomen van de aankopen krijgen we goed inzicht. Echter, ik moet eerlijk toegeven dat mijn hart sneller gaat kloppen bij het lezen over de grote $e_{c e s s}$ 
aantallen foto's die Westendorp maakte van voorwerpen en het land. Mag ik daarom zo vrij zijn nogmaals belet te vragen bij de fortuin en mij afvragen: zijn die er nog?

\section{Noten}

1. M. Draak, 'Het Rode Boekje van Mevrouw Westendorp', Aziatische Kunst 15/4 (1985), p. 9.

2. Mevrouw Françoise Barones van Lynden-Banzets schoonvader Jan Carel Elias van Lynden trouwde in 1914 met Johanna de Clerck, dochter uit het huwelijk van Catharina Engeltje Westendorp, oudere zus van Herman Karel, en Gérard Matthieu de Clercq. Mevrouw Van Lynden was goed bevriend met Betsy Westendorp, met wie zij het kunstenaarschap deelde. Ik ben mevrouw van Lynden bijzonder erkentelijk dat $z \mathrm{ij}$ de aantekeningen ter bestudering in bruikleen heeft willen geven.

3. Westendorp bewaarde zijn naamkaartje. Inada was gevestigd in de antiquairwijk Shimonzen, in Naka no cho.

4. Dagboek H.K. Westendorp, woensdag 8 oktober 1930.

5. H.F.E. Visser, 'Reisbrief uit Japan', Maandblad voor Beeldende Kunsten 7/12 (1930), p. 384.

6. 3-snarige Japanse luit.

7. Dagboek H.K. Westendorp, 2 november 1930.

8. Dagboek H.K. Westendorp, 4 november 1930.

9. Dagboek H.K. Westendorp, 31 oktober 1930.

10. Het is wel opmerkelijk dat de kritiekpunten van Westendorp overeenkomen met een recente beschouwing van het beeldje door Shimizu Masumi. Zie de vertaling 'Kijk op Japan', Aziatische Kunst 35/1 (2005), p. 24.

11. Dagboek H.K. Westendorp, 1 november 1930.

12. Dagboek H.K. Westendorp, 9 oktober 1930.

13. Dagboek H.K. Westendorp, 23 november 1930.

14. Dagboek H.K. Westendorp, 31 oktober 1930.

15. Dagboek H.K. Westendorp, 1 november 1930.

16. Dagboek H.K. Westendorp, 15 november 1930.

17. Dagboek J.E. Westendorp-Osieck., 14 november 1930.

18. K. Kobayashi, 3 Chome, Motomachi-dori, Kobe.

19. T. Kurasawa, No. 209, 1 Chome, Motomachi-dori, Kobe. 